\title{
Temporary change in personality states among social media users: effects of Instagram use on Big Five personality states and consumers' need for uniqueness
}

\author{
Dariusz Drążkowski (DD ${ }^{A, B, C, D, E, F, G}$, Sebastian Pietrzak $k^{B, F}$, Laura Mądry ${ }^{B, F}$ \\ Faculty of Psychology and Cognitive Science, Adam Mickiewicz University, Poznań, Poland
}

\section{BACKGROUND}

Research suggests that certain personality traits influence the frequency of social media use. However, the potential effect of social media use on personality states merits investigation as well, in light of the personality dynamics approach.

\section{PARTICIPANTS AND PROCEDURE}

We conducted an experimental study in which 325 Instagram users were asked to count selfies and emoticons on their Instagram profiles (experimental condition) or their phones (control condition). Subsequently, all participants responded to questions from the Big Five personality inventory and scale to measure the need for uniqueness in consumption.

\section{RESULTS}

Instagram users had a higher neuroticism state and a higher need for uniqueness compared with the controls. In terms of the other Big Five states, we observed no differences between the study conditions.

\section{CONCLUSIONS}

Our study explores the novel direction of the relationship between social media use and personality, suggesting that using Instagram can temporarily change personality states.

\section{KEY WORDS}

Big Five model; need for uniqueness in consumption; personality dynamics approach; social media; Instagram

Corresponding Author - Dariusz Drążkowski, Ph.D., Faculty of Psychology and Cognitive Science, Adam Mickiewicz University, 89AB Szamarzewskiego Str., 60-568 Poznań, Poland, e-mail: dardra@amu.edu.pl authors' Contribution - A: Study design - B: Data collection - C: Statistical analysis - D: Data interpretation .

E: Manuscript preparation · F: Literature search · G: Funds collection

TO CITE THIS ARTICLE - Drążkowski, D., Pietrzak, S., \& Mądry, L. (2022). Temporary change in personality states among social media users: effects of Instagram use on Big Five personality states and consumers' need for uniqueness.

Current Issues in Personality Psychology, 10(1), 32-38. 


\section{BACKGROUND}

In 2020, internet users worldwide spent an average of 145 minutes per day on social media (Statista, 2021). As of January 2021, Instagram had more than 2.7 billion active users (Statista, 2021). Indeed, social media platforms enjoy popular and widespread use worldwide. Among other things, researchers are interested in what motivates people to spend time on social media. They have focused on investigating which personality traits included in the Big Five model are associated with more frequent social media use. Recent meta-analysis results have summarized the links between personality traits and social media use (Huang, 2019). Most notably, higher levels of extraversion and neuroticism are associated with more frequent use of social media. The associations of the other traits in the Big Five model, namely, openness to experience, conscientiousness, and agreeableness, with social media use tend to be weaker or non-significant. The strength of the link between personality traits and social media use has also been demonstrated by research showing that digital traces of online behavior are an accurate expression of users' personalities. The predictive power of digital footprints (text and pictures) on social media over Big Five personality traits ranged from 0.29 (agreeableness) to 0.40 (extraversion) (Azucar et al., 2018).

The personality traits included in the Big Five model are not the only good predictors of social media use. For example, research also shows that as the need for uniqueness increases, so does social media use frequency (Johnson \& Ranzini, 2018). People tend to satisfy their need to be unique by being active on social media, whether by viewing other users' profiles or by publishing their content. According to the theory of uniqueness (Snyder \& Fromkin, 1977), individuals need to differentiate themselves from others when they perceive themselves as highly similar to others. Individuals reduce that unpleasant feeling of being too similar to others by expressions of their uniqueness, for instance, by wearing distinctive and unconventional clothes (Ruvio et al., 2008). Social media create social conditions that can intensify the need for uniqueness through social comparisons that indicate similarity to other users. Meanwhile, the public character of one's profile on social media enables the expression of one's uniqueness, such as through selfpresentation of one's own consumer choices.

The aforementioned studies have identified the links between the Big Five personality traits, the need for uniqueness, and social media use using a correlational approach. The assumption behind the seemingly straightforward direction of the examined relations is that certain personality traits and needs influence the increased intensity of social media use. However, research in the personality dynamics approach suggest that personality may not be the sole determinant of an individuals' specific behavior - individuals' specific behavior may change their personality (Fleeson \& Jayawickreme, 2015). The dynamic approach to personality stated that although individuals have relatively stable personality traits, their manifestation, i.e., personality states, can vary depending on the situation (Fleeson \& Jayawickreme, 2015). Thus personality states can be interpreted as an expression of a personality trait: a trait becomes realized through enacting relevant states (Fleeson et al., 2002). From another perspective, personality traits can be considered as features of the distribution of experienced personality states (Fleeson \& Jayawickreme, 2015). Personality states are short-term, concrete patterns of cognitions, affects, and behaviors that reflect how individuals are at the moment (within-person differences in personality) compared to how they are in general, which is typical for personality traits (between-person differences in personality). Personality states can be assessed using the same measures as traits (e.g., Big Five measure by the Ten Item Personality Inventory), but within a much shorter time frame (Heller et al., 2007). Within-person variation in personality states depends on the reciprocal interaction of individual behavior and situational factors (Fleeson \& Jayawickreme, 2015).

Matz and Harari (2021) demonstrated how a specific situational context could affect the Big Five personality states. Their findings showed that spending time in a particular place predicts individuals' personality states (personality state reported in current moment). Numerous specific situational contexts an individual is placed in, or the frequent activities an individual undertakes, can affect changes in personality states which over time can lead to personality trait changes. For example, a longitudinal study's empirical data demonstrate that occupational characteristics can change personality traits (Wille \& De Fruyt, 2014). Volitional efforts may also enable individuals to change their personality traits (Hudson \& Fraley, 2015). Non-clinical interventions delivered via smartphone applications have been shown to be highly effective in helping individuals change personality traits in the desired direction (Stieger et al., 2021). These tools respond to the needs of most people who want to change some aspects of their personality traits (Hudson \& Roberts, 2014).

To date, correlational studies have assumed that personality traits determine the intensity of social media use. Indeed, specific personality traits are associated with social media use (Huang, 2019). In light of the personality dynamics approach (Fleeson \& Jayawickreme, 2015), the direction of the relation between social media use and personality merits investigation. To understand the links between personality and social media use, we examined the impact of social media use on the Big Five personality states and the need for uniqueness. We aimed to 
provide insight into the relationship between social media use and personality states. Based on the personality dynamics approach, we suggest that social media use may affect personality states and, in turn, may lead to changes in personality traits over time. Thus we assume that the observed relationship between personality traits and social media use may be bidirectional. Since the extraversion and neuroticism traits correlate most strongly with social media use (Huang, 2019), it is most likely that of the other Big Five personality states, extraversion and neuroticism will be influenced mainly by social media use. In other words, the correlation between neuroticism and extraversion traits and social media use can be partly explained because social media use intensifies extraversion and neuroticism states, leading to an increase in extraversion and neuroticism traits over time. We chose to examine use of one of the most popular social media platforms - Instagram. The following hypothesis was proposed:

H1: Using Instagram increases personality states of neuroticism (H1a) and extraversion (H1b).

We further justify this hypothesis by pointing out that as neuroticism is positively linked with self-disclosure (Seidman, 2013), individuals using Instagram may activate their past experiences of self-disclosure, which in turn may exacerbate neuroticism states. Instagram use may also activate the increased tendency for social comparison, characteristic of neurotic people (Rozgonjuk et al., 2019). Since the time spent offline with friends and in public places increases the extraversion state (Matz \& Harari, 2021),

\section{Table 1}

Demographic data of the participants

\begin{tabular}{lrr}
\hline Descriptive variable & $n$ & $\%$ \\
\hline Age $(M=23.68, S D=5.86)$ & & \\
$15-20$ & 212 & 65.2 \\
$21-30$ & 24 & 7.4 \\
$31-40$ & 8 & 2.5 \\
$40+$ & & \\
Sex & 49 & 14.5 \\
$\quad$ Male & 278 & 85.5 \\
Female & & \\
Education & 9 & 2.8 \\
Elementary or occupational & 40 & 12.3 \\
$\quad$ Middle & 189 & 58.2 \\
Students & 87 & 26.8 \\
Bachelor's or higher & &
\end{tabular}

we expected that being online with other people on social media can lead to similar effects.

Research showed a positive relationship between social media use and the need for uniqueness (Johnson \& Ranzini, 2018), which is aroused when individuals perceive that they are highly similar to others (Snyder \& Fromkin, 1977). Kim's (2009) findings suggest that social media users may experience too much similarity to other users (of which there are millions), which may intensify their need for uniqueness. This need is primarily expressed in consumer behavior. We considered that the expression of the need for uniqueness could be manifested prominently through consumer behavior (e.g., by publishing photos with unique clothes) on social media. We predicted the following:

$\mathrm{H} 2$ : Using Instagram increases the need for uniqueness.

\section{PARTICIPANTS AND PROCEDURE}

\section{PARTICIPANTS}

We recruited 325 study participants through an invitation to participate in a study "exploring the relation between the type of photographs taken and personality traits" that was published on many social networking websites. A description of the age, gender and education distribution of the study participants can be found in Table 1.

\section{PROCEDURE}

Both the invitation to participate in the study and the information about the study emphasized that this study was for Instagram users only. Participants confirmed at the beginning of the study that they have an Instagram profile (in both conditions). Once the volunteers provided informed consent, they were randomly redirected to one of two different pages representing one of the two study conditions. In the experimental condition, participants were asked to review their last ten photos published on their Instagram profile. When reviewing their photos, the participants were asked to count carefully how many of their ten last photos were selfies, or photos of themselves taken by them. A proper definition of a selfie was provided to clarify the request. They were then asked to state the number of selfies. The next task was to review the last ten photos published on their Instagram account and carefully count the number of emoticons with negative (e.g., expressing sadness, anger) and positive content (e.g., expressing joy and pride) that they used in their descriptions of the photos. Subsequently, they recorded the number of negative and positive emoticons separately. Completing both tasks required them 
to spend a few minutes on Instagram. In the control condition, we asked participants to perform the same tasks as in the experimental condition, except that the selfies were those saved on their phone and the emoticons were from messages they had sent (e.g., SMS or chat messenger). Finally, all participants completed the Ten-Item Personality Inventory (TIPI) and consumers' need for uniqueness short-form scale ${ }^{1}$. At the end of the study, the participants answered a set of demographic questions.

We designed the research conditions in the way described above to force, through two bogus tasks, participants to spend a few minutes on Instagram. We chose these tasks not because they represent the most typical activities on Instagram but because they are quantifiable and require participants to spend a few minutes on Instagram, which we could confirm by checking whether they completed the tasks. It was not the activities themselves performed on Instagram (counting selfies and emoticons) that were the most important in our manipulation, but instead being in (and viewing) the Instagram environment. We assumed that it activated past experiences of typical Instagram use and accompanying changes in personality states. By designing the experimental condition in this way, we were also able to create an equivalent comparison for the results - the control group, in which participants performed the same tasks (counting selfies and emoticons) but did not do so on Instagram. Thus, only the Instagram use differentiates the two study conditions, which allows us to consider that we experimentally manipulated the independent variable: Instagram use.

\section{MEASURES}

Questions and scale instructions were adapted to allow for momentary measurement.

Personality states. Participants reported their personality states on the TIPI (Gosling et al., 2003; Łaguna et al., 2014), which could measure the Big Five dimensions: extraversion $(\alpha=.70)$, agreeableness $(\alpha=.51)$, conscientiousness $(\alpha=.64)$, emotional stability $(\alpha=.63)$, and openness to experience $(\alpha=.51)$. The TIPI consists of 10 items, and each of the five personality dimensions is measured by two items. The participants rated the extent to which ten pairs of words (e.g., "critical", "quarrelsome") applied to them on a seven-point scale ranging from 1 (strongly disagree) to 7 (strongly agree).

Consumer need for uniqueness. To assess consumers' need for uniqueness, we used two items from the consumer's need for uniqueness-short form scale by Ruvio et al. (2008): "Having an eye for products that are interesting and unusual assists me in establishing a distinctive image" and "I actively seek to develop my personal uniqueness by buying special products or brands" $(\alpha=.77)$. These items were selected as they had the highest factor loadings on the creative choice counter conformity subscale translated into Polish in our previous, unpublished study. Responses were scored on a seven-point scale ranging from 1 (strongly disagree) to 7 (strongly agree).

\section{RESULTS}

The Kolmogorov-Smirnov test showed that the dependent variables are not normally distributed $(p \leq .001)$. Therefore, to assess the significance of the difference between the two independent groups, we used the Mann-Whitney test, i.e., a non-parametric test. The descriptive statistics and results of the Mann-Whitney test with effect sizes are presented in Table 2.

The participants in the Instagram use condition reported higher levels of emotional stability (supporting H1a) and marginally higher levels of need for uniqueness (supporting H2) compared with their counterparts in the control condition. We observed no statistically significant differences between the conditions in extraversion (contrary to $\mathrm{H} 1 \mathrm{~b}$ ) and other personality states (agreeableness, conscientiousness, openness to experience).

\section{DISCUSSION}

To our knowledge, our study is the first to explore the possibility that using social media can affect the Big Five personality states and the need for uniqueness. Based on the personality dynamics approach (Fleeson \& Jayawickreme, 2015), our findings suggest that using Instagram increased neuroticism states and the need for uniqueness. Our study shed light on personality dynamics by identifying the relations between social media use and people's personality states. Previous research has examined the changing personality states through spending time in different places (Matz \& Harari, 2021). Meanwhile, our study explores the possibility of experimentally manipulated specific activities to suggest causal dependencies. Thus, we initiated exploring a new methodological approach that could enable cause-effect reasoning for future research in this area.

Our results suggest that Instagram use increased the neuroticism state. A possible explanation for this relationship is that individuals who use Instagram by viewing their photos may have activated their past experience of self-disclosure. Meanwhile, selfdisclosure is a behavior typical of highly neurotic individuals (Seidman, 2013). In our experiment, the behavioral manipulation used was relatively weak: the participants used Instagram for several minutes, focusing on completing the assigned tasks of count- 
Table 2

Descriptive statistics (mean rank and median) and Mann-Whitney $U$ test results ( $U$ statistic, the corresponding $z$, the significance value, effect size) for dependent variables

\begin{tabular}{|c|c|c|c|c|c|c|c|c|}
\hline & \multicolumn{2}{|c|}{$\begin{array}{l}\text { Instagram } \\
\text { condition } \\
(n=160)\end{array}$} & \multicolumn{2}{|c|}{$\begin{array}{c}\text { Control } \\
\text { condition } \\
(n=165)\end{array}$} & \multirow[t]{2}{*}{$U$} & \multirow[t]{2}{*}{$z$} & \multirow[t]{2}{*}{$p$} & \multirow[t]{2}{*}{$r$} \\
\hline & Mrank & Me & Mrank & Me & & & & \\
\hline \multicolumn{9}{|c|}{ Big Five personality states } \\
\hline Extraversion & 161.23 & 4.75 & 164.72 & 5.00 & 12916.00 & -0.34 & .736 & .02 \\
\hline Openness & 169.49 & 5.50 & 156.71 & 5.50 & 12161.50 & -1.24 & .216 & .07 \\
\hline Emotional stability & 150.33 & 3.50 & 175.28 & 4.00 & 11173.00 & -2.41 & .016 & .13 \\
\hline Conscientiousness & 156.77 & 5.00 & 169.05 & 5.00 & 12202.50 & -1.19 & .236 & .07 \\
\hline Agreeableness & 156.77 & 5.00 & 169.04 & 5.50 & 12203.50 & -1.19 & .235 & .07 \\
\hline $\begin{array}{l}\text { Consumers' need } \\
\text { for uniqueness }\end{array}$ & 172.71 & 3.50 & 153.59 & 3.00 & 11647.00 & -1.84 & .065 & .10 \\
\hline
\end{tabular}

ing emoticons and selfies. Meanwhile, the impact of using social media for hours at a time may have the effect of temporarily changing personality states to a much greater extent. Further, based on longitudinal studies showing that occupational work can modify personality traits after many years of work (Wille $\&$ De Fruyt, 2014), we suggested that individuals who use social media for several hours a day for many years may experience changes in their personality traits. Thus, addictive use of social media over many years may make people more neurotic.

Contrary to our expectations, Instagram use did not increase extraversion. One explanation for the failure to confirm the assumed relationship may be activities designed in the experimental and control conditions. The subjects viewed their photos and comments on Instagram in the experimental condition but did not interact with other Instagram users. Meanwhile, we assumed that it was the social environment of Instagram that could lead to an increase in extraversion. In the control condition, participants may read messages from others on the phone. Such a social activity may increase extraversion. On the other hand, it may be that online contact with other people via social media does not have the same effect on the extraversion state as offline contact, which increases the extraversion state (Matz \& Harari, 2021). Investigating such a relationship is undoubtedly an interesting direction for future research.

Our findings suggest that Instagram use intensified the need for uniqueness expressed in consumer behavior, shedding new light on the relation between the need for uniqueness and social media use (Johnson \& Ranzini, 2018). The connection may be that social media use leads to an increased need for unique- ness, such as by creating the feeling that the profile of the social media user is similar to many other profiles, according to the theory of uniqueness (Snyder \& Fromkin, 1977). Given the 1.2 billion profiles on Instagram (Statista, 2021), similarity among profiles would be inevitable, which would be felt by the platform's users when viewing their profiles. Meanwhile, the relation between the need for uniqueness and social media use (Johnson \& Ranzini, 2018) may prove that Instagram users seek to create unique profiles that allow them to differentiate themselves from the many other profiles present on the platform. Thus, viewing one's profile, while expressing and satisfying the need for uniqueness, may induce the belief that one has a great need for Most people want to change their personality to increase their well-being (Hudson \& Roberts, 2014). Recent research shows that people can volitionally change their personality traits through practicing certain activities (Stieger et al., 2021). Therefore, from a population perspective, future research should identify activities that may increase or decrease certain personality traits. Developing a list of such activities, including consumer behaviors, could yield a valuable self-help tool. Previous findings (Matz \& Harari, 2021) suggest that consumer activities in restaurants, bars, gyms, or stores lower the neuroticism of consumers who enjoy what these places have to offer. Our results suggest adding a new relation to this list: Instagram users who want to lower their neuroticism can try to limit the time spent on Instagram. One of the challenges facing researchers of the impact of consumer culture on consumers' psychological functioning is empirically determining which consumer behaviors lead to changes in personality. Our results provide 
a step toward understanding the relations mentioned above. Moreover, given that more frequent social media use (Appel et al., 2020) and higher levels of trait neuroticism (Anglim et al., 2020) are associated with lower well-being, we suggest that more frequent social media use may heighten neuroticism, which may lead to reduced well-being. Thus, future studies may examine a new potential mechanism explaining the link between social media use and well-being: personality states change.

The present study has a few limitations and specific implications for future research. First, the sample consisted mostly of female students; thus, the results may not be generalizable to a broader population. Future research should include other groups to determine the effects on less-educated peers, males, and other age cohorts. Second, another limitation is how the subject's activities in the experimental and control groups were designed. In the experimental condition, the participants' tasks were to count selfie photos and emoticons on Instagram. These are not typical social media activities - the tasks did not encourage more specific social media behavior, such as reading other people's posts. In contrast, the activity in the control condition involved counting photos taken on the phone and reading SMS or Messenger messages on the phone. However, phone use may not be a neutral activity and may affect personality states. Furthermore, although the essential function of Messenger chat is the same as SMS messaging, Messenger use can also be considered a part of social media activities. Therefore, future research should consider more typical activities undertaken on social media in the experimental condition and more neutral activities in the control condition. Third, as we did not control the personality states before applying the experimental manipulation, the conclusion about observing causal relationships is not fully grounded. Future studies should be longitudinally designed with a pretest of personality states to strengthen our conclusions about causal relationships. Lastly, we examined how social media use could affect personality at the state level. Future research could examine the long-term impact of social media use on personality traits. Examining the impact of social media use on personality states or traits other than those included in this study, such as narcissism, would also be an exciting research direction.

\section{ENDNOTE}

1 Two other scales (measuring social media selfpresentation and appearance contingency of selfworth) were also included in the procedure, as part of a separate research project (not yet published) examining determinants of publishing selfie photos on Instagram.

\section{RefERENCES}

Anglim, J., Horwood, S., Smillie, L. D., Marrero, R. J., \& Wood, J. K. (2020). Predicting psychological and subjective well-being from personality: a metaanalysis. Psychological Bulletin, 146, 279-323. https://doi.org/10.1037/bul0000226

Appel, M., Marker, C., \& Gnambs, T. (2020). Are social media ruining our lives? A review of meta-analytic evidence. Review of General Psychology, 24, 60-74. https://doi.org/10.1177/1089268019880891

Azucar, D., Marengo, D., \& Settanni, M. (2018). Predicting the Big 5 personality traits from digital footprints on social media: a meta-analysis. Personality and Individual Differences, 124, 150-159. https://doi.org/10.1016/j.paid.2017.12.018

Fleeson, W., \& Jayawickreme, E. (2015). Whole trait theory. Journal of Research in Personality, 56, 82-92. https://doi.org/10.1016/j.jrp.2014.10.009

Fleeson, W., Malanos, A. B., \& Achille, N. M. (2002). An intraindividual process approach to the relationship between extraversion and positive affect: Is acting extraverted as "good" as being extraverted? Journal of Personality and Social Psychology, 83, 1409-1422. https://doi.org/10.1037/00223514.83.6.1409

Gosling, S. D., Rentfrow, P. J., \& Swann, W. B. Jr (2003). A very brief measure of the Big Five personality domains. Journal of Research in Personality, 37, 504-528. https://doi.org/10.1016/S0092-6566 (03)00046-1

Heller, D., Komar, J., \& Lee, W. B. (2007). The dynamics of personality states, goals, and well-being. Personality and Social Psychology Bulletin, 33, 898-910. https://doi.org/10.1177/0146167207301010

Huang, C. (2019). Social network site use and Big Five personality traits: a meta-analysis. Computers in Human Behavior, 97, 280-290. https://doi. org/10.1016/j.chb.2019.03.009

Hudson, N. W., \& Fraley, R. C. (2015). Volitional personality trait change: Can people choose to change their personality traits? Journal of Personality and Social Psychology, 109, 490-507. https:// doi.org/10.1016/j.jrp.2014.10.009

Hudson, N. W., \& Roberts, B. W. (2014). Goals to change personality traits: Concurrent links between personality traits, daily behavior, and goals to change oneself. Journal of Research in Personality, 53, 68-83. https://doi.org/10.1016/j.jrp.2014.08.008

Johnson, B. K., \& Ranzini, G. (2018). Click here to look clever: Self-presentation via selective sharing of music and film on social media. Comput ers in Human Behavior, 82, 148-158. https://doi. org/10.1016/j.chb.2018.01.008

Kim, J. (2009). "I want to be different from others in cyberspace": The role of visual similarity in virtual group identity. Computers in Human Behavior, 25, 88-95. https://doi.org/10.1016/j.chb.2008.06.008 
Łaguna, M., Bąk, W., Purc, E., Mielniczuk, E., \& Oleś, P. K. (2014). Short measure of personality TIPI-P in a Polish sample. Annals of Psychology, 17, 421-437.

Matz, S. C., \& Harari, G. M. (2021). Personality-place transactions: Mapping the relationships between Big Five personality traits, states, and daily places. Journal of Personality and Social Psychology, 120, 1367-1385. https://doi.org/10.1037/pspp0000297

Rozgonjuk, D., Ryan, T., Kuljus, J. K., Täht, K., \& Scott, G. G. (2019). Social comparison orientation mediates the relationship between neuroticism and passive Facebook use. Cyberpsychology: Journal of Psychosocial Research on Cyberspace, 13, 2. https://doi.org/10.5817/CP2019-1-2

Ruvio, A., Shoham, A., \& Brenčič, M. M. (2008). Consumers' need for uniqueness: Short-form scale development and cross-cultural validation. International Marketing Review, 25, 33-53. https://doi. org/10.1108/02651330810851872

Seidman, G. (2013). Self-presentation and belonging on Facebook: How personality influences social media use and motivations. Personality and Individual Differences, 54, 402-407. https://doi.org/ 10.1016/j.paid.2012.10.009

Snyder, C. R., \& Fromkin, H. L. (1977). Abnormality as a positive characteristic: The development and validation of a scale measuring need for uniqueness. Journal of Abnormal Psychology, 86, 518-527. https://doi.org/10.1037/0021-843X.86.5.518

Statista (2021). Internet usage worldwide - statistics $\&$ facts. Retrieved from https://www.statista.com/ topics/1145/internet-usage-worldwide/

Stieger, M., Flückiger, C., Rüegger, D., Kowatsch, T., Roberts, B. W., \& Allemand, M. (2021). Changing personality traits with the help of a digital personality change intervention. Proceedings of the National Academy of Sciences, 118, e2017548118. https://doi.org/10.1073/pnas.2017548118

Wille, B., \& De Fruyt, F. (2014). Vocations as a source of identity: Reciprocal relations between Big Five personality traits and RIASEC characteristics over 15 years. Journal of Applied Psychology, 99, 262-281. https://doi.org/10.1037/a003491 